\title{
The state of coenopopulations of the vegetatively-semimobile species of Thymus in Southern Siberia
}

\author{
Evgeniya Talovskaya ${ }^{1 *}$, Irina Barsukova $^{2}$ \\ ${ }^{1}$ Central Siberian Botanical Garden of the SB RAS, 630090 Novosibirsk, Russia \\ ${ }^{2}$ Katanov Khakass State University, 655017 Abakan, Russia
}

\begin{abstract}
The state of coenopopulations of vegetatively-semimobile dwarf shrubs Thymus iljinii, T. minussinensis, T. mongolicus, T. petraeus, widely distributed in steppe communities in Southern Siberia was studied. Adults of the species are a clump consisting of a primary and several partial bushes. For individuals characterized by the preservation of the main root, weak vegetative growth and reproduction, slow seizure of territory. The complex of data on organizational and population characteristics is analyzed. It is established that the real optimum state of coenopopulations of the studied species is achieved in the petrophytic variants of steppes located on the slopes of mountains. Conditions of highmountain steppe and alpine plant communities are unfavorable for Thymus.
\end{abstract}

In the study of natural ecosystems and forecasting their development in recent years, researchers are increasingly using the concept of population organization of ecosystems. One of the approaches of the concept is the study of coenopopulations of species and their stability in a particular area $[1,2]$.

Species of Thymus L. are widely distributed in Southern Siberia. They are found in mountain and flat steppes, forest steppes and forests. As shown by our study, in Southern Siberia, the most Thymus species-are vegetatively-semimobile dwarf shrubs [3]. Adult individuals are characterized by the preservation of the main root, weak vegetative growth and reproduction, slow capture of the territory due to the close location of the partial structures to the primary bush. On the territory of the republics of Khakassia, Altai and Tuva we studied cenopopulations (CP) of four vegetatively-semimobile dwarf shrubs: $T$. iljinii Klok. et Schost. (CP 1), T. minussinensis Serg. (CP 2), T. mongolicus (Ronn.) Ronn. (CP 3-5), T. petraeus Serg. (CP 6-8). The majority of CP (1-3, 6-8) was studied in the conditions of petrophytic variants of steppes located in the middle or upper parts of the gravelly slopes or along the aligned peaks of the hills. The total projective cover (OPP) of grass in communities ranges from 55 to $70 \%$, the projective cover (PP) of Thymus from 4 to $7 \%$. Coenopopulations 4 and 5 were studied in the alpine environment: $\mathrm{CP} 4$ - in petrophytic version alpine meadows (OPP grass does not exceed $20 \%$, PP $1 \%$ ), the CP 5 in the condition petrophytic alpine steppe (OPP grass $55 \%$, PP $3 \%$ ). The state of the

\footnotetext{
* Corresponding author: kolegova e@mail.ru
} 
Thymus CP was assessed according to organism and population characteristics [4]. The diameter and phytomass of the bush of adult generative individuals, length of generative shoots, number of compound skeletal axes were chosen as organizational features; as population - ecological density of $\mathrm{CP}$, phytomass of plants per $\mathrm{m}^{2}$; the proportion of adult generative individuals in the CPU, the proportion of immature individuals and virginal states.

The assessment of the state of CP on the basis of organizational characteristics showed that their ecological optimum was in the petrophytic variant of steppe and was noted only in one CP 7 (Fig.). This CP is studied in the territory Nature reserve "Khakass", the area "Oglahty". The absence of anthropogenic action, leading to a violation of the integrity of individuals, increases the vitality of individuals and the values of almost all signs of the organism. However, competition of the species (ecological density of $38.9 \mathrm{ind} . / \mathrm{m}^{2}$, the CP 55 , the projective cover of the rockslide with outcrops up to $25 \%$ ) in the condition of low available substrate, hinder the growth of individuals in the $\mathrm{CP} 7$, the formation of new centres of consolidation, and maximize the values of their diameter. Individuals in the $\mathrm{CP}$ $1-3,6,8$ are close to the optimal condition, they are located in the petrophytic steppes. Most of their parameters have average values. The conditions prevailing in the highmountain steppe (CP 5) and in the alpine meadow (CP 4) are unfavorable for the development of individuals Thymus: all biometric parameters are sharply reduced.

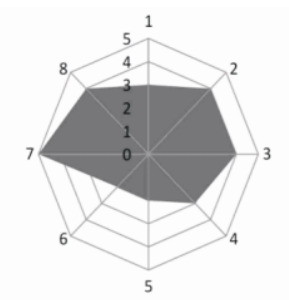

CP 1

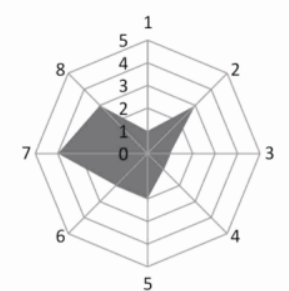

CP 5

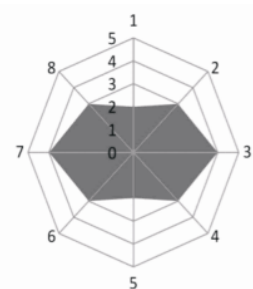

CP 2

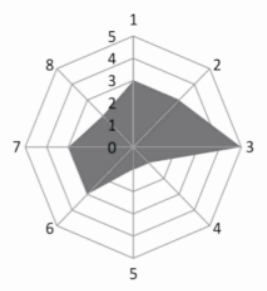

CP 6

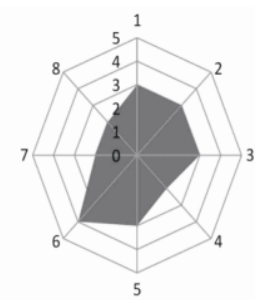

CP 3

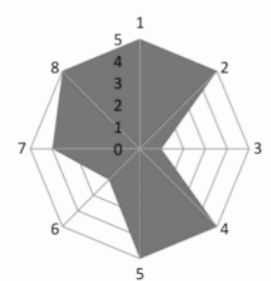

$\mathrm{CP} 7$

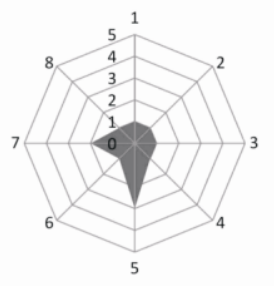

CP 4

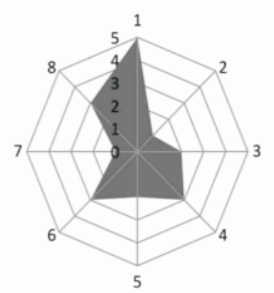

CP 8

Fig. Assessment of the state of species of the Thymus coenopopulations (signs of organism: 1 - the number of skeletal axes, units; 2 - the length of generative shoots, $\mathrm{cm} ; 3$ - diameter of adult generative individuals, sm; 4 - phytomass in adult generative individuals, g; signs of population: 5 phytomass species, g; 6 - proportion of adult generative individuals, $\% ; 7$ - the proportion of immature individuals and virginal, \%; 8 - environmental $\mathrm{CP}$ density ind. $/ \mathrm{m}^{2}$ ).

Analysis of population characteristics showed that in the most optimal conditions is CP 7 , it is characterized by high rates of phytomass and ecological density, a large proportion of young individuals. The state of CP 1-5 is close to optimal due to a rather high proportion of im-v individuals (CP 1, 2, 5) and $\mathrm{g}_{2}$ individuals (CP 3), as well as the phytomass of individuals (CP 3 and 4). In the CP 6 , and 8 values of the majority of the population signs are dramatically reduced. This is due to different reasons. CP 6 is located at the top of the hill, where there is a constant blowing of snow in winter, lack of moisture in the summer. Under these conditions, there is a low viability of young individuals, reducing the duration of the adult generative state, which leads to a decrease in the ecological density and 
phytomass of individuals. In $\mathrm{CP} 8$, the decrease in population characteristics is associated with the accumulation of dead grass (projective cover up to $20 \%$ ), which prevents the development of young individuals and their accumulation in the CP. Thus, the state of the CP 6 and 8 is approaching severe.

The coincidence of ecological and phytocenotic optima was noted only for one CP located in the petrophytic steppe in the reserve (CP 7). The condition of most of the CP is close to optimal (CPU 1-3). In the conditions of petrophytic variants of steppes on hilltops or with the accumulation of dead grass, along with the optimal state of individuals, the state of the $\mathrm{CP}$ is approaching to pessimal (CP 6 and 8). On the contrary, in the conditions developing in high-mountain plant communities, the state of individuals is pessimal at the optimal state of the CP (CP 4 and 5).

The analysis showed that the real optimum of vegetatively-semimobile shrubs of the Thymus in Southern Siberia is achieved mainly in the steppe zone of vegetation, in petrophytic steppes located on the slopes of the mountains. The conditions of highmountain steppe and alpine plant communities in general are unfavorable for the studied Thymus species. The real optima of the organism and the population in such conditions do not coincide, and the values of the corresponding indicators are low.

The work was carried out with the financial support of the grant of RFBR within the framework of project № 18-04-00621 and State Assignment of Central Siberian Botanical Garden SB RAS № AAAA-A17-117012610053-9

\section{References}

1. B. Walker, Conservation Biology, 9(4) (1995).

2. L.B. Zaugol'nova, T.Yu. Braslavskaya, Assessment and preservation of biodiversity of forest cover in European Russian nature reserves (Moscow, Nauchnyy mir, 2000)

3. E.B. Talovskaya, V.A. Cheryomushkina, J. Ecosystem Ecology, 2(3) (2017)

4. L.B. Zaugol'nova, Population structure of seed plants and problems of their monitoring: abstract of thesis of Doctor of Biological Sciences (St Peterburg University, Saint-Petersburg, 1994) 